Pacific Journal of Mathematics

DEDEKIND'S PROBLEM: MONOTONE BOOLEAN FUNCTIONS
ON THE LATTICE OF DIVISORS OF AN INTEGER 


\title{
DEDEKIND'S PROBLEM: MONOTONE BOOLEAN FUNCTIONS ON THE LATTICE OF DIVISORS OF AN INTEGER
}

\author{
PAUL Hess
}

This paper is concerned with the combinatorial problem of counting the number of distinct collections of divisors of an integer $N$ having the property that no divisor in a collection is a multiple of any other. It is shown that if $N$ factors into primes $N=p_{1}^{a}{ }_{1} p_{2}^{a}{ }_{2} \cdots p_{n}^{a}$ the number of distinct collections of divisors with the stated property does not exceed $\left(\sum_{i=1}^{n} a_{i}-n+3\right)^{M}$, where $M$ is the maximum coefficient in the expansion of the polynomial

$\left(1+x+x^{2}+\cdots+x^{a_{1}}\right)\left(1+x+x^{2}+\cdots+x^{a_{2}}\right) \cdots\left(1+x+x^{2}+\cdots+x^{a_{n}}\right)$.

In the special case where $N$ is squarefree the problem is equivalent to that of counting the number of "Sperner families" on $n$ letters, for which G. Hansel obtained the upper bound $3^{M_{n}}$, where $M_{n}$ is the binomial coefficient $\left(\begin{array}{c}n \\ {[n / 2]}\end{array}\right)$; the result in this paper is then a generalization of Hansel's theorem to the non-squarefree case.

The problem has also been formulated as that of counting the number of families consisting of incomparable subsets of a set of $n$ objects (the objects of course corresponding to the primes in the number-theoretic formulation), with the variation that each object may appear in a set with a specifically limited number of repetitions (these limits corresponding to the prime exponents).

Notation. Given $n$ letters $x_{1}, x_{2}, \cdots, x_{n}$, and $n$ positive integers $a_{1}, a_{2}, \cdots, a_{n}$, consider the lattice consisting of all terms $\left(x_{1}^{j_{1}} x_{2}^{j_{2}} \cdots x_{n}^{j_{n}}\right)$ in the polynomial $\prod_{i=1}^{n}\left(\sum_{k=0}^{\alpha_{i}} x_{i}^{k}\right)$, with the partial ordering defined $\left(x_{1}^{j_{1}} x_{2}^{j_{2}} \cdots x_{n}^{j_{n}}\right) \leqq\left(x_{1}^{k_{1}} x_{2}^{k_{2}} \cdots x_{n}^{k_{n}}\right)$ if $j_{i} \leqq k_{i}$ for all $i$. A single term $X=$ $\left(x_{1}^{j_{1}} x_{2}^{j_{2}} \cdots x_{n}^{j_{n}}\right)$ in this lattice will be referred to as a "set", the empty set $\phi$ denoting the term with all exponents $j_{1}, j_{2}, \cdots, j_{n}$ equal to zero. If $X=\left(x_{1}^{j_{1}} x_{2}^{j_{2}} \cdots x_{n}^{j_{n}}\right)$, the notation $\left(X, x_{k}^{c}\right)$ will indicate the set $\left(x_{1}^{j_{1}} x_{2}^{j_{2}}, \cdots x_{k}^{j_{k}+c} \cdots x_{n}^{j_{n}}\right)$, and the exponent sum $j_{1}+j_{2}+\cdots+j_{n}$ will be written $|X|$.

A monotone Boolean function is defined to be a function taking the values 0 or 1 on each set of this lattice with the property that $f(X) \leqq f(Y)$ if $X \leqq Y$. The problem of counting the number of monotone Boolean functions on this lattice is then equivalent to the problem concerning collections of divisors of $N$ stated at the begin- 
ning.

(1) The lattice defined above can be partitioned into chains, constructed inductively:

If $n=1$, the chain covering consists of the single chain $\phi \subseteq$ $\left(x_{1}\right) \subseteq\left(x_{1}^{2}\right) \subseteq \cdots \subseteq\left(x_{1}^{a_{1}}\right)$.

If $n>1$, assume the chain covering has already been constructed on the $n-1$ letters $x_{1}, \cdots, x_{n-1}$. Each chain $C: X_{1} \subseteq X_{2} \subseteq \cdots \subseteq$ $X_{r}$ of the covering on $n-1$ letters gives rise to the chains

$$
\begin{aligned}
& X_{1} \subseteq X_{2} \subseteq \cdots \subseteq X_{r} \leqq\left(X_{r}, x_{n}\right) \subseteq\left(X_{r}, x_{n}^{2}\right) \subseteq \cdots \subseteq\left(X_{r}, x_{n}^{a_{n}}\right) \\
& \left(X_{1}, x_{n}\right) \leqq\left(X_{1}, x_{n}^{2}\right) \leqq \cdots \subseteq\left(X_{1}, x_{n}^{a}\right) \leqq\left(X_{2}, x_{n}^{a}\right) \leqq \cdots \subseteq\left(X_{r-1}, x_{n}^{a} n\right) \\
& \left(X_{2}, x_{n}\right) \leqq\left(X_{2}, x_{n}^{2}\right) \leqq \cdots \leqq\left(X_{r-1}, x_{n}^{a_{n}-1}\right) \\
& \text { terminating in } \\
& \left(X_{r-1}, x_{n}\right) \subseteq \cdots \subseteq\left(X_{r-1}, x_{n}^{a_{n}-(r-2)}\right) \text { if } 2 \leqq r \leqq a_{n} \\
& \text { or in } \\
& \left(X_{a_{n}}, x_{n}\right) \subseteq\left(X_{a_{n}+1}, x_{n}\right) \subseteq \cdots\left(X_{r-1}, x_{n}\right) \text { if } r>a_{n} \text {. }
\end{aligned}
$$

If $r=1$, the chain $C$ gives rise only to the chain

$$
X_{1} \subseteq\left(X_{1}, x_{n}\right) \subseteq \cdots \subseteq\left(X_{1}, x_{n}^{a}{ }^{a}\right) \text {. }
$$

EXAMPLES. If $n=1, a_{1}=2$, the covering consists of the single chain $\phi \subseteq\left(x_{1}\right) \subseteq\left(x_{1}^{2}\right)$.

If $n=2, a_{1}=2, a_{2}=4$, the covering consists of the three chains

$$
\begin{aligned}
& \phi \leqq\left(x_{1}\right) \leqq\left(x_{1}^{2}\right) \leqq\left(x_{1}^{2} x_{2}\right) \leqq\left(x_{1}^{2} x_{2}^{2}\right) \leqq\left(x_{1}^{2} x_{2}^{3}\right) \leqq\left(x_{1}^{2} x_{2}^{4}\right) \\
& \left(x_{2}\right) \leqq\left(x_{2}^{2}\right) \subseteq\left(x_{2}^{3}\right) \leqq\left(x_{2}^{4}\right) \leqq\left(x_{1} x_{2}^{4}\right) \\
& \left(x_{1} x_{2}\right) \subseteq\left(x_{1} x_{2}^{2}\right) \subseteq\left(x_{1} x_{2}^{3}\right) \text {. }
\end{aligned}
$$

An easy induction on $n$ suffices to show that each chain contains a set $X$ for which the exponent sum

$$
|X|= \begin{cases}\sum_{i=1}^{n} a_{i} / 2 \text { if } \sum_{i=1}^{n} a_{i} \text { is even } \\ \left(\sum_{i=1}^{n} a_{i}+1\right) / 2 \text { if } \sum_{i=1}^{n} a_{i} \text { is odd }\end{cases}
$$

and that all sets in the lattice appear once and only once in the coverning. It follows that the number of chains in the covering is given by $M$, the maximum coefficient in the expansion of the polynomial $\prod_{i=1}^{n}\left(\sum_{k=0}^{\alpha_{i}} x_{i}^{k}\right)$. (The coefficient of $x^{j}$ in this polynomial is the number of sets in the lattice with exponent sum $j$.)

A theorem of Dilworth [2], states that a partially ordered set with $k$ but not $k+1$ incomparable elements can be covered by $k$ 
chains. The chain covering defined above is the covering whose existence is guaranteed by Dilworth's theorem.

The set function $\sigma$. If three sets $X \subseteq Y \subseteq Z$ appear in succession within a chain, we define $\sigma(X)$ to be the set $X+(Z-Y)$. $\sigma(X)$ is undefined if $X$ is not at least three places from the end of its chain.

EXAMPLES. $\quad \phi \subseteq\left(x_{1}\right) \subseteq\left(x_{1}^{2}\right) ; \sigma(\phi)=\left(x_{1}\right)$

$$
\left(x_{1}^{2} x_{2}^{3}\right) \subseteq\left(x_{1}^{2} x_{2}^{4}\right) \subseteq\left(x_{1}^{2} x_{2}^{4} x_{3}\right) ; \sigma\left(x_{1}^{2} x_{2}^{3}\right)=\left(x_{1}^{2} x_{2}^{3} x_{3}\right) .
$$

If $X \subseteq Y \subseteq Z$ are three sets in succession within a chain in the covering, it is easy to see that if $\sigma(X)=Y$, then all the letters in $Z$ are also letters in $Y$. This situation will be abbreviated " $\sigma(X)=$ next", and we note that the length $l$ of the longest possible sequence in a chain of the form $\cdots X_{i+1} \subseteq X_{i+2} \subseteq \cdots \subseteq X_{i+l} \cdots$ where $X_{i+1} \neq \phi$ and all $X$ in the sequence are composed of the same letters, is $\sum_{i=1}^{n} a_{i}-n+1$.

Within the chain covering (1), define an ordering of the chains as follows: If $n=1, C_{1}$ is the single chain $\phi \subseteq\left(x_{1}\right) \subseteq\left(x_{1}^{2}\right) \subseteq \cdots \subseteq\left(x_{1}^{a_{1}}\right)$, and inductively if $n>1$, and $C_{1}^{\prime}, C_{2}^{\prime}, \cdots C_{k}^{\prime}$ are the ordered chains in the covering for the $n-1$ letters $x_{1}, \cdots, x_{n-1}$, and if $C_{j}^{\prime}$ gives rise to the chains $C_{j_{1}}, C_{j_{2}}, \cdots, C_{j_{j}}$ in the covering on $n$ letters in the sequence in which they appear in the definition (1), then let $C_{11}, C_{12}$, $\cdots, C_{1 l_{1}} ; C_{21}, C_{22}, \cdots, C_{2 l_{2}} ; \cdots ; C_{k 1}, C_{k 2}, \cdots, C_{k l_{k}}$ be the ordering of the chains $C_{1}, C_{2}, \cdots, C_{M}$ in the $n$-letter covering. (In other words, simply order the chains as they appear in the inductive definition). An easy induction on $n$ then establishes the following property of the function $\sigma:(2)$ If $\sigma(X)$ is defined and " $\neq$ next", and $X$ appears in chain $C_{i}, \sigma(X)$ in chain $C_{j}$, then $j>i$.

Proof of (2). Induction on $n$. The statement is true for $n=1$ vacuously. Consider the chain on $n-1$ letters $X_{1} \subseteq X_{2} \subseteq \cdots \subseteq X_{r}$ giving rise to the chains on $n$ letters

$$
\begin{aligned}
& X_{1} \subseteq X_{2} \subseteq \cdots \subseteq X_{r} \subseteq\left(X_{r}, x_{n}\right) \subseteq \cdots \subseteq\left(X_{r}, x_{n}^{a} n\right) \\
& \left(X_{1}, x_{n}\right) \subseteq\left(X_{1}, x_{n}^{2}\right) \subseteq \cdots \subseteq\left(X_{1}, x_{n}^{a}\right) \leqq\left(X_{2}, x_{n}^{a}\right) \leqq \cdots \subseteq\left(X_{n-1}, x_{n}^{a}\right) \\
& \left(X_{j-1}, x_{n}\right) \subseteq \cdots\left(X_{j-1}, x_{n}^{a} n^{-(j-2)}\right) \subseteq\left(X_{j}, x_{n}^{a_{n}-(j-2)}\right) \subseteq \cdots \subseteq\left(X_{r-1}, x_{n}^{a_{n}-(j-2)}\right) .
\end{aligned}
$$

In the first chain above, if $\sigma\left(X_{k}\right)$ is defined and " $\neq$ next", $k \leqq r-2$, so that $\sigma\left(X_{k}\right)$ is in a later $n-1$ chain by induction, therefore in a later $n$-chain. $\sigma\left(X_{r}\right)$ " $=$ next" and the same holds for $\sigma\left(X_{r}, x_{n}\right)$, $\sigma\left(X_{r}, x_{n}^{2}\right)$, etc. $\sigma\left(X_{r-1}\right)=\left(X_{r-1}, x_{n}\right)$ which is in a later $n$-chain. In 
subsequent chains, $\sigma\left(X_{j-1}, x_{n}^{a_{n}-(j-1)}\right)=\left(X_{j}, x_{n}^{a_{n}-(j-1)}\right)$ which appears in the chain immediately following. $\sigma\left(X_{i}, x_{n}^{a_{n}-(j-2)}\right)$, where $i \geqq j-1$, if defined and " $\neq$ next", is the set $\left(\sigma\left(X_{i}\right), x_{n}^{a_{n}-(j-2)}\right)$ where $\sigma\left(X_{i}\right)$ " $\neq$ next". By induction, $\sigma\left(X_{i}\right)$ is in a later $n-1$ chain so that $\left(\sigma\left(X_{i}\right)\right.$, $\left.x_{n}^{a_{n}-(j-2)}\right)$ is in a later $n$-chain, which completes the proof of the assertion.

(3) If $C$ is a chain in the covering and $f$ is a monotone Boolean function already defined on all sets $\sigma(W)$, where $W$ is any set in the chain $C$ for which $\sigma(W)$ is defined and " $\neq$ next", then the number of possible definitions for $f$ on the chain $C$ does not exceed $\sum_{i=1}^{n} a_{i}-n+3$.

Proof of (3). Let the chain $C$ consist of $l$ sets $W_{1} \subseteq W_{2} \subseteq \cdots \subseteq$ $W_{l}$. Suppose $\sigma(W)$ is undefined or " = next" for all $W$ in the chain $C$. Then if $l \geqq 3, W_{2} \neq \phi$ and $W_{2} \cdots W_{l}$ are sets consisting of the same letters. Then the number of ways of defining a monotone Boolean function on the chain is at most $l+1 \leqq \sum_{i=1}^{n} a_{i}-n+3$. Otherwise, let $W_{m}$ be the $W$ farthest to the right in the chain for which $f(\sigma(W))=0$, and $W_{k}$ the $W$ farthest to the left for which $f(\sigma(W))=1$. Either $m$ or $k$ exists. If $k$ does not exist, then $m$ does. In this case $f\left(\sigma\left(W_{m}\right)\right)=0$ and since $W_{m} \subseteq \sigma\left(\left(W_{m}\right)\right), f$ is undetermined only on the portion of the chain $W_{m+1}, W_{m+2}, \cdots, W_{m+l}$. But $\sigma$ is undefined or "=next" on these sets, so that $W_{m+2} \cdots W_{l}$ are sets consisting of the same letters (or $W_{m+1} \cdots W_{l}$ is shorter than 3 sets in length). Thus $f$ is undetermined on at most $\sum_{i=1}^{n} a_{i}-n+2$ sets and the number of ways of defining $f$ is at most $\sum_{i=1}^{n} a_{i}-n+$ 3 (either 0 throughout the chain, or $\sum_{i=1}^{n} a_{i}-n+2$ choices for the position of the 1 farthest to the left). A similar argument takes care of the case where $m$ does not exist and $k$ does. If $m$ and $k$ both exist, first suppose $m<k$. Then we have $f=0$ on the sets $W_{m}, W_{m-1}, \cdots$, down to $W_{1}$, and $f=1$ on the sets $W_{k+2}, W_{k+3}, \cdots$ up to $W_{l}$. In this case $W_{m+2} \cdots W_{k-1} W_{k} W_{k+1}$ are all sets consisting of the same letters, so that the length of the segment on which $f$ is undetermined, $(k+1)-(m+1)+1$, is at most $\sum_{i=1}^{n} a_{i}-n+2$, and as before the number of possible definitions of $f$ on the chain is at most $\sum_{i=1}^{n} a_{i}-n+3$. The final possibility is $m \geqq k$, but by definition of $m$ and $k, m \neq k$ and obviously $m$ cannot exceed $k+1$. The situation is then: $W_{1} \subseteq \cdots \subseteq W_{k} \subseteq W_{m} \subseteq W_{m+1} \subseteq \cdots \subseteq W_{l}, m=k+1$, $f\left(\sigma\left(W_{k}\right)\right)=1$ and $f\left(\sigma\left(W_{m}\right)\right)=0$ so that $f=1$ on the sets $W_{m+1} \cdots W_{l}$, $f=0$ on the sets $W, \cdots, W_{k}, W_{m}$, and $f$ is completely predetermined on the chain in this case.

Conclusion. $\left(\sum_{i=1}^{n} a_{i}-n+3\right)^{M}$, where $M$ is the maximal coeffi- 
cient in the expansion of $\left(1+x+\cdots+x^{a_{1}}\right)\left(1+x+\cdots+x^{a_{2}}\right) \cdots$ $\left(1+x+\cdots+x^{a_{n}}\right)$ is an upper bound on the number of monotone Boolean functions on the lattice of divisors of $N=p_{1}^{a_{1}} p_{2}^{a_{2}} \cdots p_{n}^{a_{n}}$.

Proof. Let $C_{1}, C_{2}, \cdots, C_{M}$ be the ordered chains in the covering. On the last chain, the function $\sigma$ is undefined or "=next" throughout. (Otherwise, according to (2), for $X$ in the chain $C_{M}, \sigma(X)$ would appear in a later chain which is impossible.) It then follows from (3) that the number of ways of defining $f$ on $C_{m}$ does not exceed $\sum_{i=1}^{n} a_{i}-n+3$. On chain $C_{M-1}$, if $X$ is a set in this chain for which $\sigma(X)$ is defined and " $\neq$ next", then according to $(2) \sigma(X)$ appears in the chain $C_{M}$. Thus $f(\sigma(X))$ is already defined for all such $X$ in the chain $C_{M-1}$, and from (3) there are at most $\sum_{i=1}^{n} a_{i}-$ $n+3$ possible definitions of $f$ on $C_{M-1}$. Continuing in this way to the first chain $C_{1}$ gives the upper bound stated.

\section{REFERENCES}

1. G. Hansel, Sur le nombre des fonctions booléennes monotones de $n$ variables, C. R. Acad. Sci. Paris, 262, 1088.

2. R. P. Dilworth, A decomposition theorem for partially ordered sets, Annals of Mathematics, January, 1950.

Not cited in this paper, but related:

3. D. Kleitman, On Dedekind's Problem: The Number of Monotone Boolean Functsons, Proc. Amer. Math. Soc., 21 (1969), 677-682.

4. H. N. Shapiro, On the counting problem for Monotone Boolean functions, Comm. Pure and Applied Math., XXIII, (1970), 299-312.

Received April 6, 1978 and in revised form September 14, 1978.

COOPER UNION

Eighth Street and Fourth Avenue

NEW YoRK, NY 10003 



\title{
PACIFIC JOURNAL OF MATHEMATICS
}

\section{EDITORS}

\author{
DONALD BABBITT (Managing Editor) \\ University of California \\ Los Angeles, CA 90024 \\ HUGo ROSSI \\ University of Utah \\ Salt Lake City, UT 84112 \\ C. C. MOORE \\ University of California \\ Berkeley, CA 94720
}

J. DugundJI

Department of Mathematics

University of Southern California

Los Angeles, CA 90007

R. FinN and J. Milgram

Stanford University

Stanford, CA 94305

\section{ASSOCIATE EDITORS}
E. F. BECKENBACH
B. H. Neumann
F. WolF
K. YOSHIDA

\section{SUPPORTING INSTITUTIONS}

\author{
UNIVERSITY OF BRITISH COLUMBIA \\ CALIFORNIA INSTITUTE OF TECHNOLOGY \\ UNIVERSITY OF CALIFORNIA \\ MONTANA STATE UNIVERSITY \\ UNIVERSITY OF NEVADA, RENO \\ NEW MEXICO STATE UNIVERSITY \\ OREGON STATE UNIVERSITY \\ UNIVERSITY OF OREGON
}

UNIVERSITY OF SOUTHERN CALIFORNIA

STANFORD UNIVERSITY

UNIVERSITY OF HAWAII

UNIVERSITY OF TOKYO

UNIVERSITY OF UTAH

WASHINGTON STATE UNIVERSITY

UNIVERSITY OF WASHINGTON

The Supporting Institutions listed above contribute to the cost of publication of this Journal, but they are not owners or publishers and have no responsibility for its content or policies.

Mathematical papers intended for publication in the Pacific Journal of Mathematics should be in typed form or offset-reproduced, (not dittoed), double spaced with large margins. Please do not use built up fractions in the text of the manuscript. However, you may use them in the displayed equations. Underline Greek letters in red, German in green, and script in blue. The first paragraph or two must be capable of being used separately as a synopsis of the entire paper. Please propose a heading for the odd numbered pages of less than 35 characters. Manuscripts, in triplicate, may be sent to any one of the editors. Please classify according to the scheme of Math. Reviews, Index to Vol. 39. Supply name and address of author to whom proofs should be sent. All other communications should be addressed to the managing editor, or Elaine Barth, University of California, Los Angeles, California, 90024.

50 reprints to each author are provided free for each article, only if page charges have been substantially paid. Additional copies may be obtained at cost in multiples of 50 .

The Pacific Journal of Mathematics is issued monthly as of January 1966. Regular subscription rate: $\$ 72.00$ a year (6 Vols., 12 issues). Special rate: $\$ 36.00$ a year to individual members of supporting institutions.

Subscriptions, orders for numbers issued in the last three calendar years, and changes of address should be sent to Pacific Journal of Mathematics, P.O. Box 969, Carmel Valley, CA 93924, U.S.A. Older back numbers obtainable from Kraus Periodicals Co., Route 100, Millwood, NY 10546.

PUBLISHED BY PACIFIC JOURNAL OF MATHEMATICS, A NON-PROFIT CORPORATION

Printed at Kokusai Bunken Insatsusha (International Academic Printing Co., Ltd.). 8-8, 3-chome, Takadanobaba, Shinjuku-ku, Tokyo 160, Japan.

Copyright (C) 1979 by Pacific Journal of Mathematics Manufactured and first issued in Japan 


\section{Pacific Journal of Mathematics}

\section{Vol. 81, No. $2 \quad$ December, 1979}

Ersan Akyildiz, Vector fields and equivariant bundles ............... 283

Ehrhard Behrends, The centralizer of tensor products of Banach spaces ( $a$ function space representation) ......................... 291

Geoffrey R. Burton, Congruent sections of a convex body ............. 303

John Warnock Carlson, $H$-closed and countably compact extensions ...... 317

Robert Charles Carlson, Eigenfunction expansions for selfadjoint

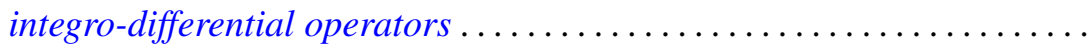

Robert Damiano, Coflat rings and modules.

Eric Karel van Douwen and Washek (Vaclav) Frantisek Pfeffer, Some properties of the Sorgenfrey line and related spaces ................

Uri Elias, Necessary conditions and sufficient conditions for disfocality and

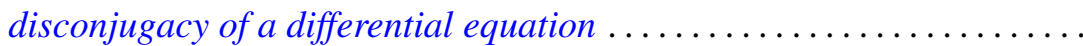

V. L. (Vagn Lundsgaard) Hansen, Polynomial covering spaces and homomorphisms into the braid groups .......................

Paul Hess, Dedekind's problem: monotone Boolean functions on the lattice

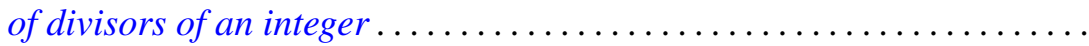

Alan Hopenwasser and David Royal Larson, The carrier space of a reflexive

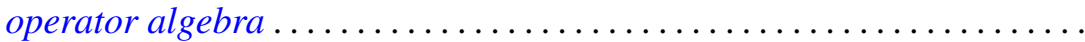

Kyung Bai Lee, Spaces in which compacta are uniformly regular $G_{\delta} \ldots \ldots$.

Claude Levesque, A class of fundamental units and some classes of

Jacobi-Perron algorithms in pure cubic fields...

Teck Cheong Lim, A constructive proof of the infinite version of the

Belluce-Kirk theorem ..........................

Dorothy Maharam and A. H. Stone, Borel boxes

Roger McCann, Asymptotically stable dynamical systems are linear

Peter A. McCoy, Approximation and harmonic continuation of axially symmetric potentials in $E^{3} \ldots \ldots \ldots \ldots \ldots \ldots \ldots$

Takahiko Nakazi, Extended weak-* Dirichlet algebras ....

Carl L. Prather, On the zeros of derivatives of balanced trigonometric polynomials ................................

Iain Raeburn, An implicit function theorem in Banach spaces...

Louis Jackson Ratliff, Jr., Two theorems on the prime divisors of zeros in completions of local domains...

Gloria Jean Tashjian, Cartesian-closed coreflective subcategories of

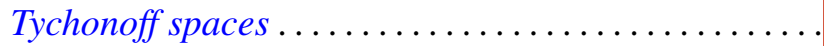

Stephen Edwin Wilson, Operators over regular maps.... . . 